\title{
Unmanned Aerial Vehicles in Environmental Monitoring-An Efficient Way for Remote Sensing
}

\author{
Tamás Fráter ${ }^{1}$, Tatjána Juzsakova ${ }^{2}$, János Lauer $^{3}$, László Dióssy ${ }^{4}$ and Ákos Rédey ${ }^{4}$ \\ 1. Directorate of Plant Protection, National Food Chain Safety Office, Soil Conservation and Agri-environment, Pesticide Analytical \\ Laboratory, Velence 2481, Hungary \\ 2. University of Pannonia, Veszprém 8200, Hungary \\ 3. Fire-Moon Ltd., Pápa 8500, Hungary \\ 4. Chianti 3D Ltd., Veszprém 8200, Hungary
}

\begin{abstract}
Airborne photographs can be expediently used in environmental monitoring; e.g., in the surveillance of the state of natural reserve areas, such as wetlands; or in the measurement and mapping of pollutants, such as oil spills on a lake or sea. A new and cost-effective platform of airborne remote sensing is the UAV (unmanned aerial vehicle) or drone. In this experimental work, aerial photos were made in Bakony Mountains using three UAVs equipped with small HD (high definition) cameras; resolution: 1,280 $\times$ 720 pixels. Within the framework of this work, a small lake was photographed, where the beginning of eutrophication was detected. This hardly can be observed from ground, however, it is visible on the aerial photos. The airborne surveillance of areas of ragweed (Ambrosia sp.) populations was also investigated. It was found that both UAVs are feasible for these tasks, and the application of these platforms for environmental monitoring is advantageous, especially in case of natural reserve areas since those are very silent and - contrary to big aircrafts and helicopters - do not disturb the ecology even in natural reserve areas and the people living there. Moreover, those could be operated in a very flexible and economic way, and the aerial photos taken are highly informative.
\end{abstract}

Key words: Remote sensing, UAV, aerial photographing, eutrophication, ragweed.

\section{Introduction}

Airborne monitoring or airborne remote sensing is a very useful tool in environmental monitoring if information is needed on a large territory within a short period of time. The only limiting factor is the cost, which could be high. For conventional monitoring, it is needed to hire an airplane. A manned aircraft or helicopter needs fuel, well-trained pilot and an airbase, which could be far away from the working area. This makes the fuel costs even higher, thus, the overall operational costs of the conventional airborne monitoring are high. In Hungary, it is typically around 5,000-6,000 USD $\cdot \mathrm{h}^{-1}$ for a helicopter and 1,000 $\mathrm{USD} \cdot \mathrm{h}^{-1}$ for a small aircraft (Cessna). However, the size (and weight) of the high-resolution cameras and

Corresponding author: Tamás Fráter, Ph.D., research field: UAVs in environmental monitoring. E-mail: tamasfrater@gmail.com. other sensors have shown a significant decreasing trend during the last decades, giving an opportunity to use them onboard of small UAV (unmanned aerial vehicles) $[1,2]$. The use of UAVs is increasing, not only in the military applications, but in civilian sector as well $[3,4]$. The costs are significantly lower (by about a magnitude), and the flexibility of the application is much higher than that of the big aircrafts due to the lack of airbase need [2].

Several types of airborne monitoring are known, which can be divided into three main types: photogrammetry [1-9], sensor mapping [10-13] and sampling $[14,15]$. In this paper, only the photogrammetry is dealt with. In photogrammetry, the information is image-type. These images could be high-resolution conventional photos [1-5, 9] or lower-resolution photos but from a special, well-defined spectral range (multi/hyperspectral 
imaging in visible, IR/UV (infrared or ultraviolet) bands) [6-8]. In both cases, two perspectives are possible: perspective from bird's eye view or from vertical angle. The first one is simple, it provides rapid information and it is very easy to use if the information obtained is to be immediately evaluated e.g., in case of emergency operations. The latter one is often used in multispectral imaging, the photos can be used in GIS (geo-information system) by converting the photos into orthographic projection and using them as "map layers", e.g., if a pollutant identification and its distribution should be determined.

The airborne monitoring can be used in different types of environmental monitoring from disaster emergency actions to the monitoring of pollutants or natural reserve areas. In case of emergency/disaster situations, a significant advantage of the airborne monitoring is that no human presence/involvement is required. Only the device is subjected to the impacts of the disaster, e.g., radiation or toxic gases. Another advantage is that from a bird's eye view, more details are visible, which are very useful in the organization of the rescue measures (Fig. 1) [10, 12, 16].

This perspective is utilizable in conventional environmental monitoring as well, e.g., in case of checking a dam, a mining spill, tail gases, etc.. In these cases, some critical points are not detectable from ground view, however, from the air, everything is visible and can be checked (Fig. 2).

The protection of natural reserve areas is an important task to keep the planet for the next generations. Aerial photographs can be used as well for monitoring of

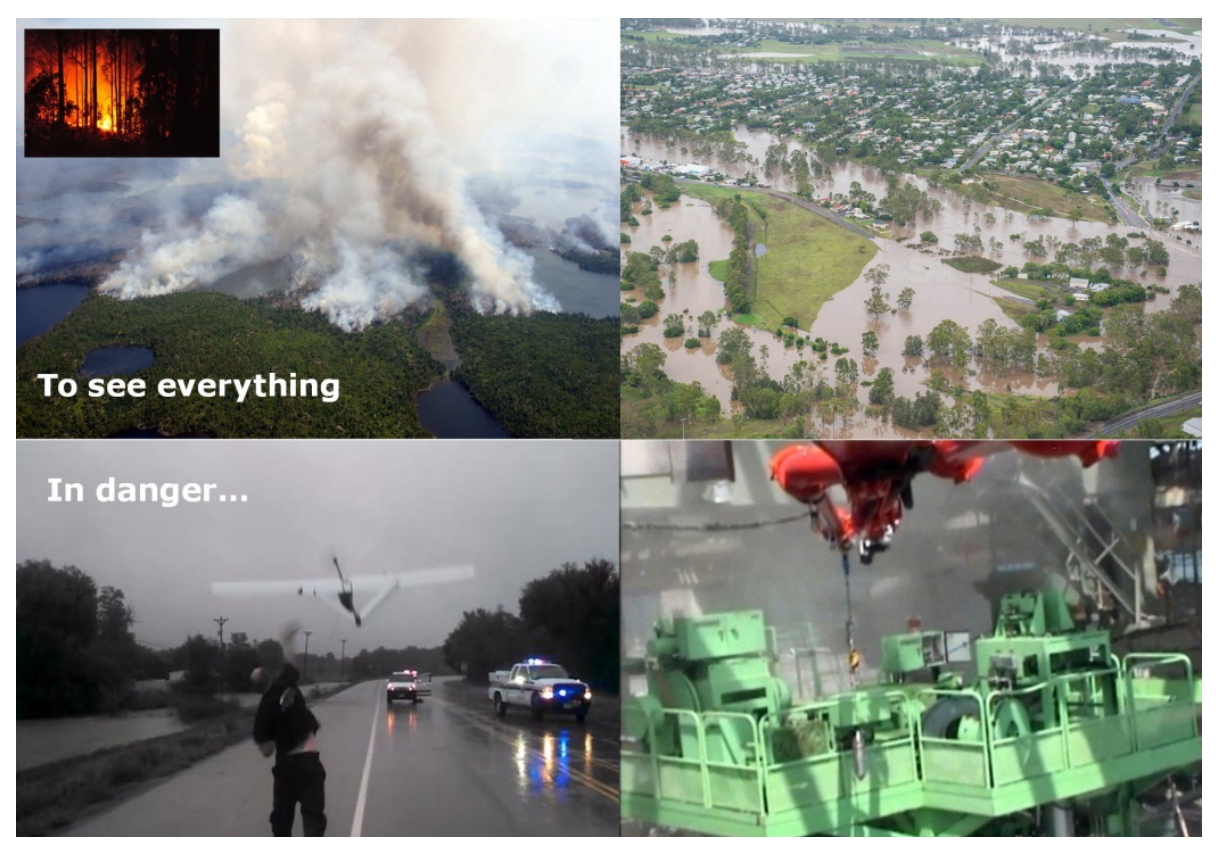

Fig. 1 Application of UAVs in disaster management.

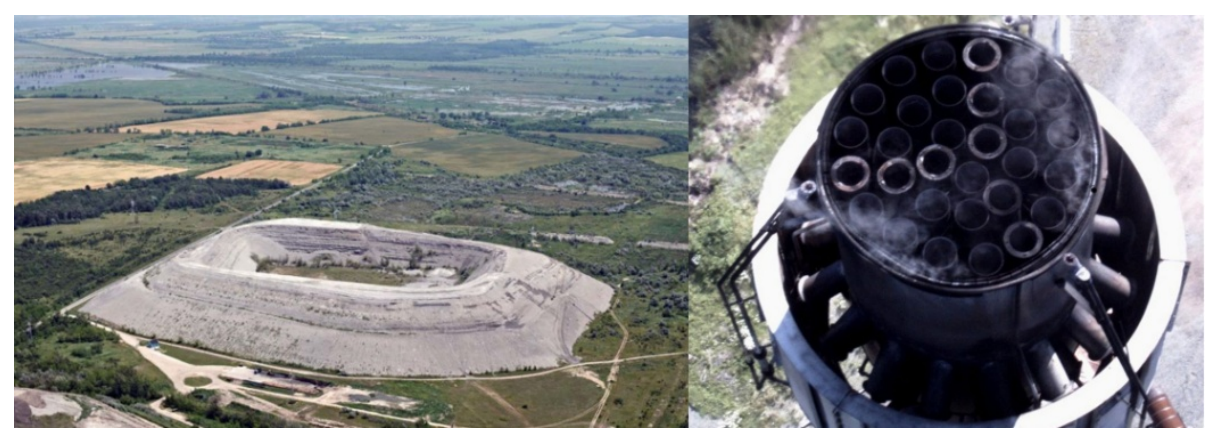

Fig. 2 Application of UAVs in facility monitoring. 


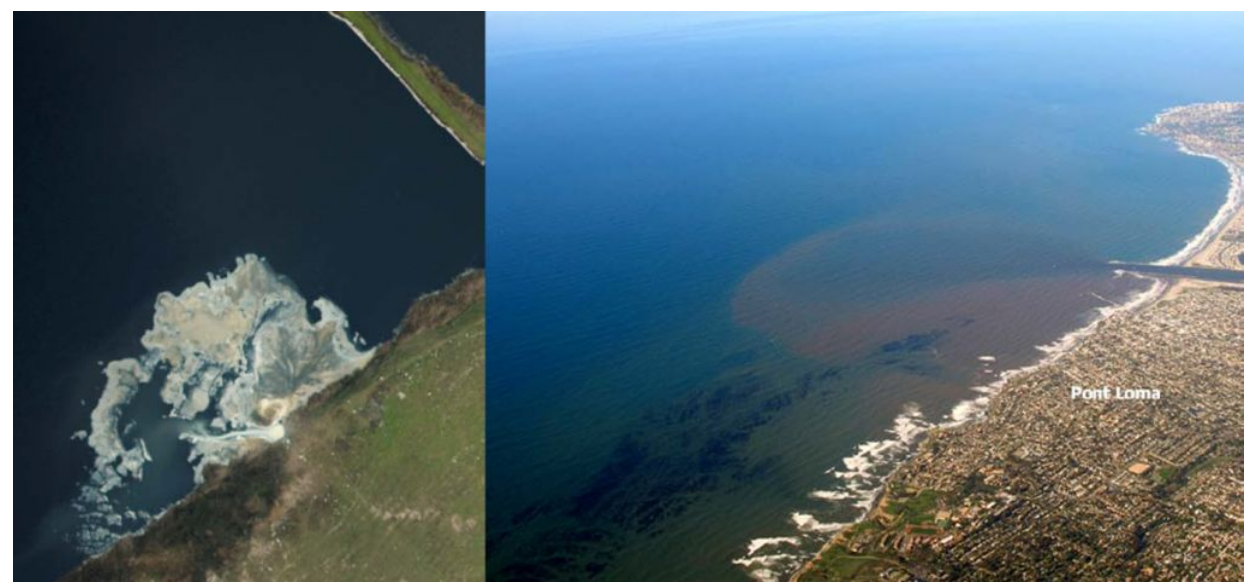

Fig. 3 Application of aerial photographing in pollution monitoring.

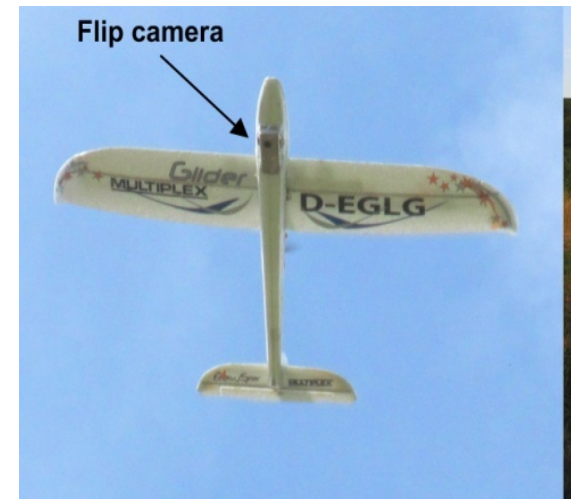

(a)

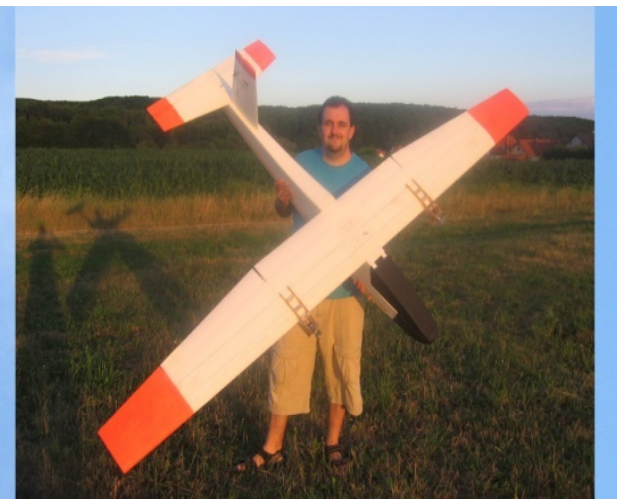

(b)

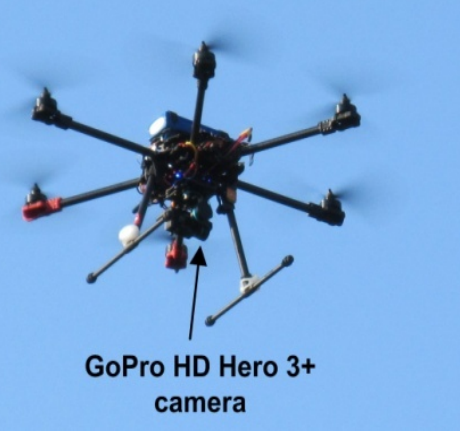

(c)

Fig. 4 The UAVs used in the experiments: (a) MULTIPLEX Easy Star II; (b) STYROMAN Smile; (c) TAROT 690S.

Table 1 Most important properties of the three UAVs.

\begin{tabular}{llll}
\hline & MULTIPLEX Easy Star II & STYROMAN Smile & TAROT 690S \\
\hline Wingspan $(\mathrm{m})$ & 1.4 & 2.7 & 1.3 \\
Payload $(\mathrm{g})$ & 300 & 2,000 & 3,500 \\
Weight $(\mathrm{g})$ & 1,000 & 4,500 & $>5,000$ \\
Material & Plastic foam (Elapor) & Plastic foam (EPP (expanded polypropylene)) & Carbon composite \\
\hline
\end{tabular}

wildlife or vegetation $[6,17]$. In the latter case, multispectral imaging is very informative. In pollution monitoring, both conventional and hyperspectral types of imaging are usable. In case of conventional photographs, only the visible pollutants (indicated by colour difference) or the impacts of the pollution (foaming, algae growth, etc.) are detectable (Fig. 3), while using hyperspectral, especially UV/IR remote sensing, other pollutants are transformed into "visible" range (e.g., oil spills) and the concentration of the pollutants can be evaluated $[18,19]$. The previously mentioned sensor remote sensing or sampling methods are also widely utilizable technologies in pollution monitoring [10-15].

\section{Material and Methods}

For the experimental work, three UAVs were purchased: a MULTIPLEX Easy Star II, a STYROMAN Smile (both of them are fixed wing aircrafts) and a TAROT $690 \mathrm{~S}$ hexacopter (Fig. 4). The most important properties of these UAVs are indicated in Table 1. The UAVs were equipped with brushless electric motors and were controlled by a $2.4 \mathrm{GHz} \mathrm{RC}$ remote control system (Futaba ${ }^{\circledR}$ FASST System). 
In case of the fixed wing aircrafts, a lightweight camera (FLIP MinoHD type, resolution $720 \times 1,280$ pixels) was used for imaging. The camera was normally positioned in the nose section of the UAV as seen in Fig. 4 (left side). The angle of down looking was altered between $2^{\circ}$ and $10^{\circ}$. Alternatively, the camera mount could be fixed on the belly of the plane: using this set up vertical angle, photographs were taken.

In case of the hexacopter, a high-resolution (5 megapixel) camera (GoPro HD Hero 3+) was used for imaging. The angle was alterable without any barriers.

\section{Results and Discussion}

The flights were carried out in the area of Bakony
Mountains, in Hungary. Several aerial photographs were taken on forests, agricultural fields and ecological important territories like wetlands. Some examples are shown in Fig. 5.

In the evaluation of the photographs, one of the investigated wetlands (Csehbánya Lakes) was found interesting, since a significant part of the lake only the northern part) exhibited the signs of eutrophication. The growth of algae is hardly detectable from the shore of the lake (ground view), however, it is clearly visible from the air (Fig. 6). The detected phenomenon was photographed again in late summer (August) when the algae population shows seasonal maximum (Fig. 7).

A control investigation was carried out in early

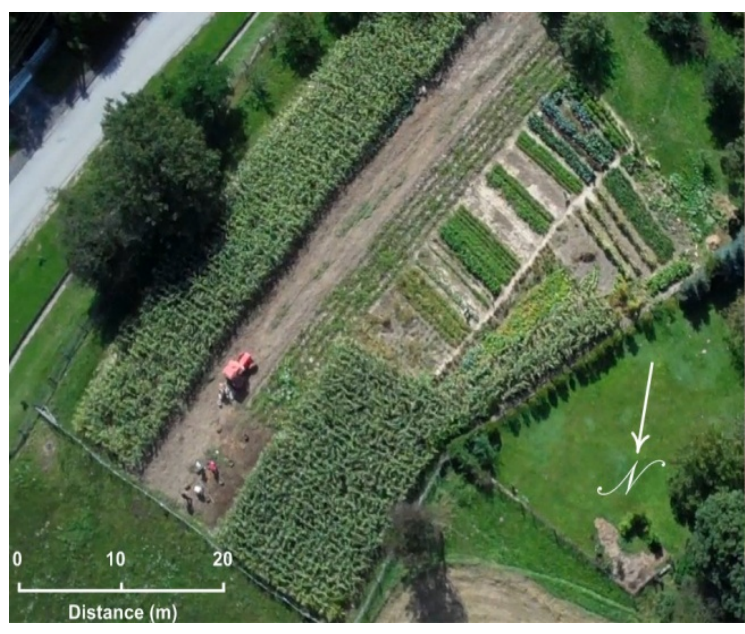

(a)

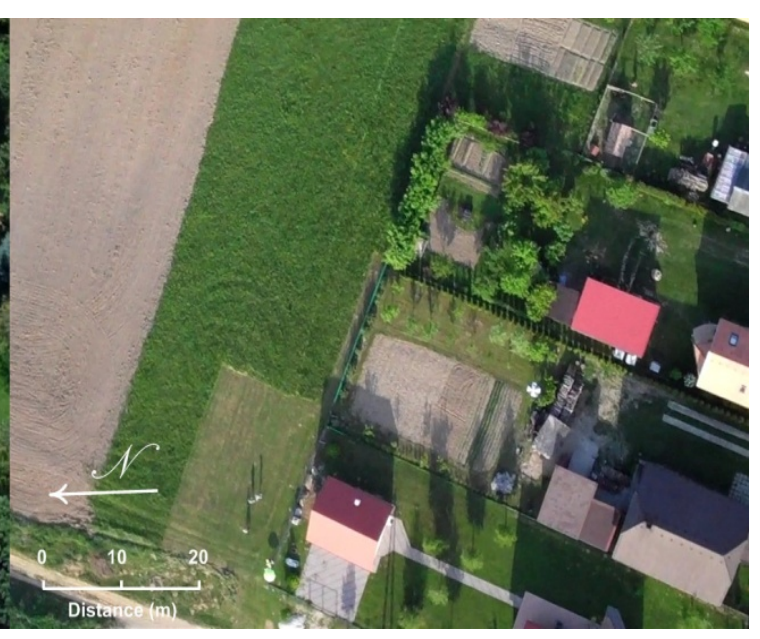

(b)

Fig. 5 Vertical axis photos of different land uses in Bakony Mountains: (a) a farm landscape; (b) village.

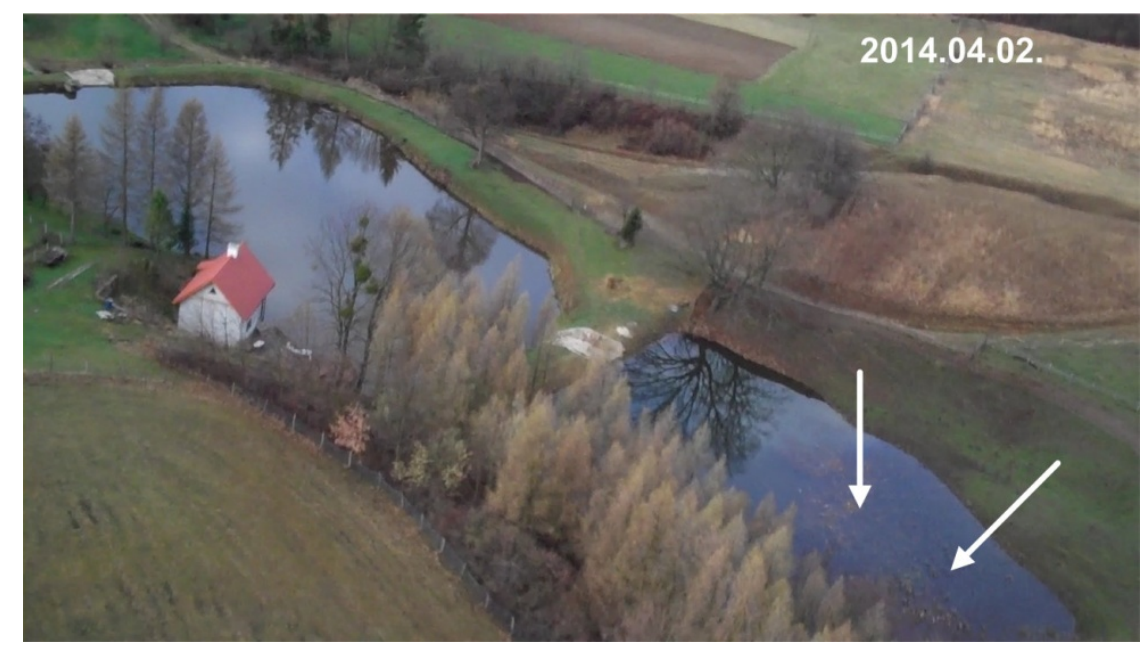

Fig. 6 Eutrophication in Csehbánya Lakes detected from the air. 


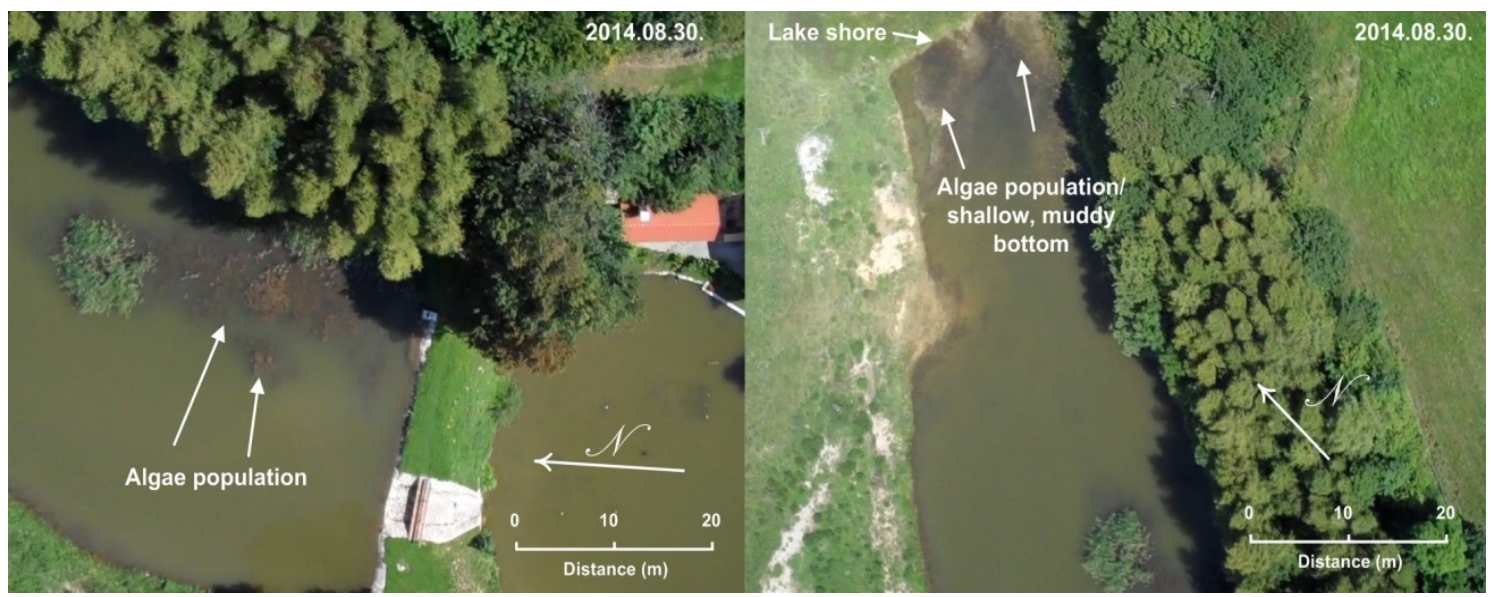

Fig. 7 Eutrophication and siltation in the northern lake of Csehbánya Lakes in late summer.

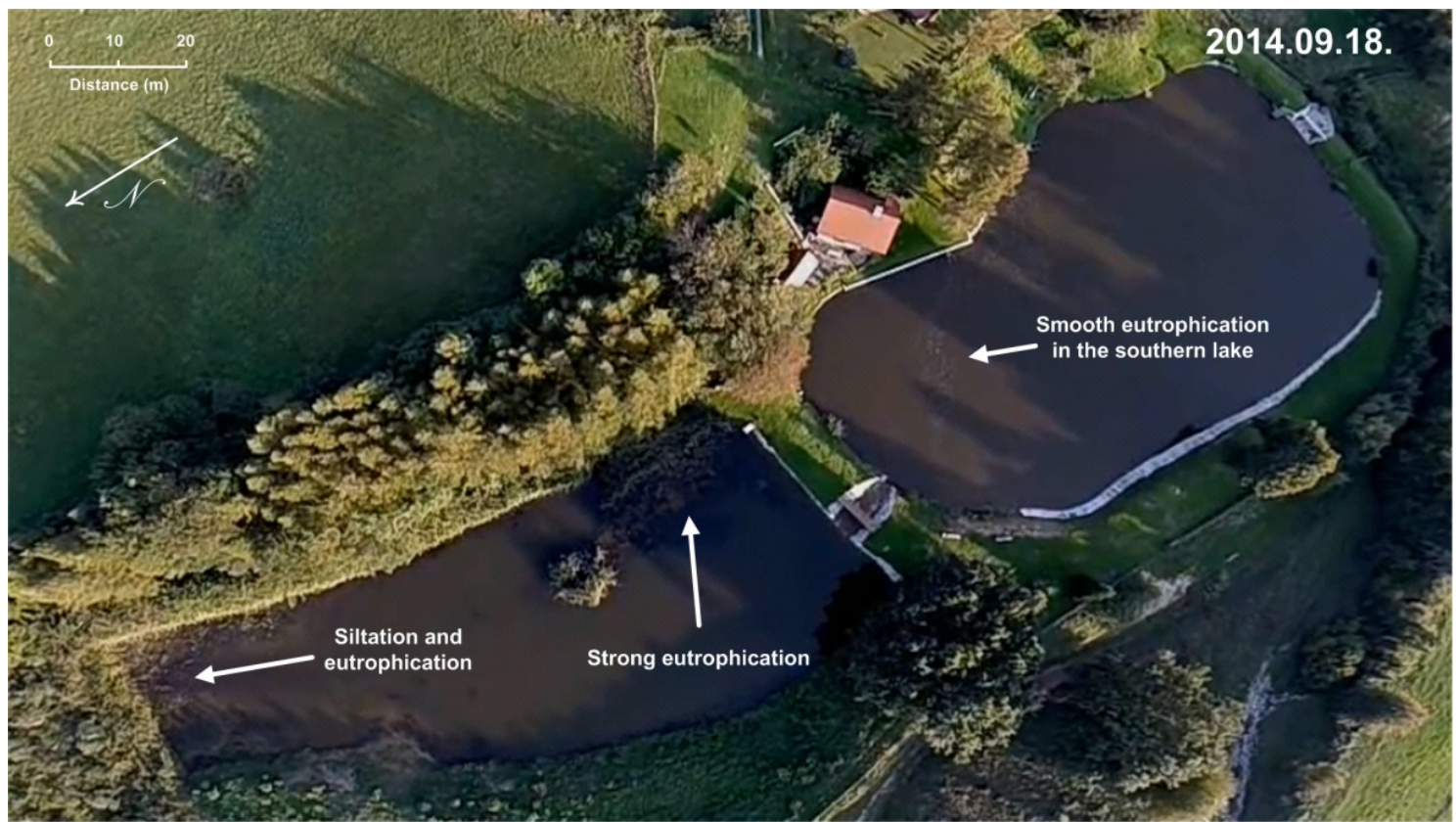

Fig. 8 Eutrophication and siltation in the northern lake of Csehbánya Lakes in early autumn.

autumn (middle of September) using the high-resolution GoPro camera and the more maneuverable hexacopter (Fig. 8).

Another project was the investigation of the usability of UAVs for the surveillance of ragweed (Ambrosia sp.). The pollen of ragweed is strongly allergic for human, its reduction is important for the human health. Recently, the government has been using helicopters for the surveillance of the larger ragweed populations in order to organize the protection more efficiently (this monitoring work is performed by the Government Office of County Fejér,
Directorate of Plant Protection and Soil Conservation). UAVs provide a more cost-effective alternative for this aim since they do not need any airfield, they could be operated for lower costs (which is advantageous, even for small villages possessing smaller budgets), and due to the electric motors, they are very silent, so the noise level to the inhabitants of the town/village is negligible (contrary conventional helicopters). An example of the photos made from the UAV Easy Star II is shown in Fig. 9.

It was concluded that the detection of ragweed is possible using these photos, however, the margins of 


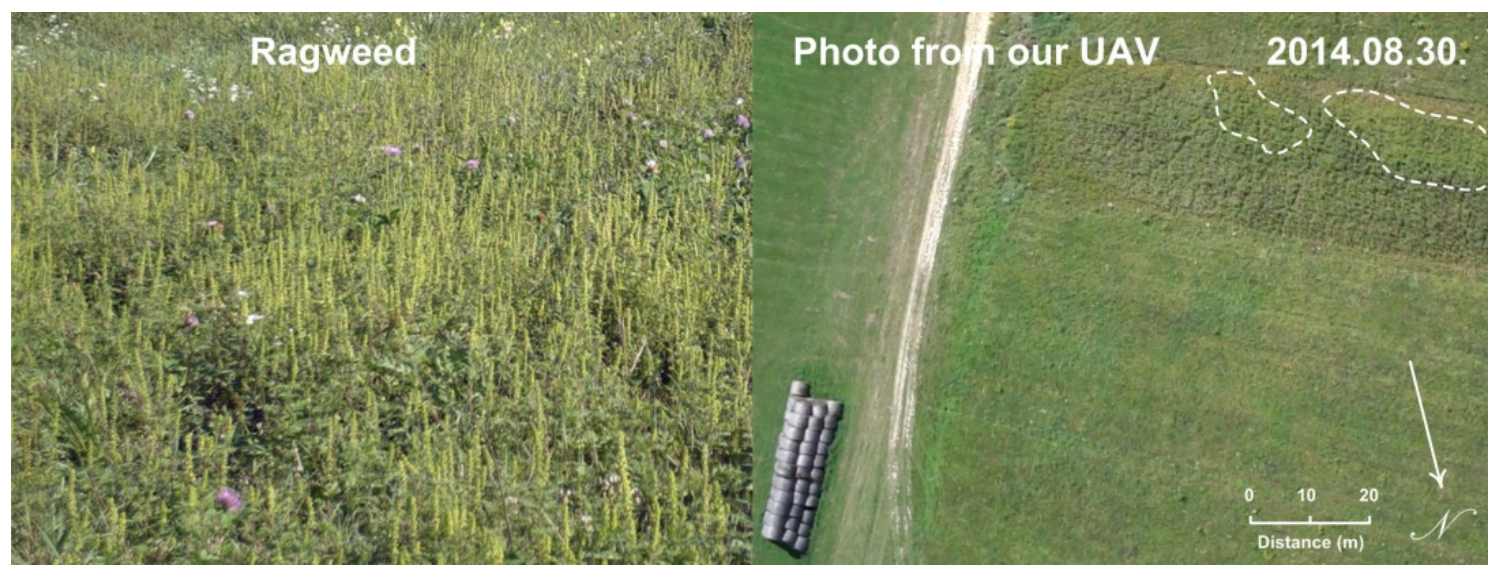

Fig. 9 Ragweed monitoring using aerial photographing from MULTIPLEX Easy Star II.

the populations are not clear enough (the contrast is not strong enough). However, this UAV-based airborne imagery method for ragweed monitoring is improvable and shows more opportunities by using more sophisticated methods (e.g., hyperspectral imaging or digital image processing methods, using a comparison to ground reference points, etc.). Since these preliminary experiments showed promising results, the experiments will be continued in the next 2 years as well.

\section{Conclusions}

It was concluded that all UAVs are suitable for taking vertical axis photos as well. Especially the hexacopter showed good flexibility in application, since this could be operated from a $20 \mathrm{~m} \times 20 \mathrm{~m}$ open square. The noise level was found to be very low in all cases due to the electric motors, making those applicable over nature conservation areas as well.

Based on the successful results with this technique using single HD camera, the photogrammetric survey will be continued in Csehbánya Lakes and it is planned to extend this work to other wetlands and natural reserve areas as well. In addition to the HD photographing, the project is planned to be continued with other high performance cameras and sensors to build up a complete "environmental sensing package" for the unmanned aerial vehicles of this research group.

\section{Acknowledgments}

Technical support of Herend Model Club is gratefully acknowledged. Special thanks are due to Lajos Huszár, Tamás Balogh and Alex Takács.

\section{References}

[1] Eisenbeiss, H. 2009. "UAV Photogrammetry." Dissertation, Eidgenössische Technische Hochschule, Zürich.

[2] Sauerbier, M., Siegrist, E., Eisenbeiss, H., and Demir, N. 2011. "The Practical Application of UAV-Based Photogrammetry under Economic Aspects." The International Archives of the Photogrammetry, Remote Sensing and Spatial Information Sciences 38: 45-50.

[3] Eissenbeiss, H. 2011. "The Potential of Unmanned Aerial Vehicles for Mapping." Photogrammetrische Woche 11: 135-45.

[4] Grenzdörffer, G. J., and Niemeyer, F. 2011. "UAV Based BRDF-Measurements of Agricultural Surfaces with PFIFFIKUS." The International Archives of the Photogrammetry, Remote Sensing and Spatial Information Sciences 38: 229-34.

[5] Haala, N., Cramer, M., Weimer, F., and Trittler, M. 2011. "Performance Test on UAV-Based Photogrammetric Data Collection." The International Archives of the Photogrammetry, Remote Sensing and Spatial Information Sciences 38: 7-12.

[6] Kelcey, J., and Lucieer, A. 2012. "Sensor Correction of a 6-Band Multispectral Imaging Sensor for UAV Remote Sensing." Remote Sensing 4: 1462-93.

[7] Laliberte, A. S., Goforth, M. A., Steele, C. M., and Rango, A. 2011. "Multispectral Remote Sensing from Unmanned Aircraft: Image Processing Workflows and Applications for Rangeland Environments." Remote Sensing 3: 2529-51. 
[8] Suárez, L., Zarco-Tejada, P. J., González-Dugo,V., Berni, J. A. J., Sagardoy, R., Morales, F., and Fereres, E. 2010. "Detecting Water Stress Effects on Fruit Quality in Orchards with Time-Series PRI Airborne Imagery." Remote Sensing of Environment 114: 286-98.

[9] Turner, D., Lucieer, A., and Watson, C. 2012. "An Automated Technique for Generating Georectified Mosaics from Ultra-High Resolution Unmanned Aerial Vehicle (UAV) Imagery, Based on Structure from Motion (SfM) Point Clouds.” Remote Sensing 4: 1392-410.

[10] Daniel, K., Dusza, B., Lewandowski, A., and Wietfeld, C. 2009. "A System-of-Systems MUAV Remote Sensing Architecture for Disaster Response." In Proceeding of Systems Conference, 2009 3rd Annual IEEE, 196-200.

[11] Rojas, M., Alexander, J., Motta, N., Gonzalez, L. F., Corke, P., and Depari, A. 2012. "Towards the Development of a Gas Sensor System for Monitoring Pollutant Gases in the Low Troposphere Using Small Unmanned Aerial Vehicles.” Accessed March 14, 2015. http://eprints.qut.edu.au/52042/1/Malaver_A_Gas_sensor _system_for_a_UAV_environmental_monitoring_WRE M_Sidney_11072012.pdf.

[12] Towler, J., Krawiec, B., and Kochersberger, K. 2012. "Radiation Mapping in Post-Disaster Environments Using an Autonomous Helicopter." Remote Sensing 4: 1995-2015.

[13] Watts, A. C., Ambrosia, V. G., and Hinkley, A. E. 2012. "Unmanned Aircraft Systems in Remote Sensing and Scientific Research: Classification and Considerations of Use.” Remote Sensing 4: 1671-92.

[14] Pöllänen, R., Toivonen, H., Peräjärvi, K., Karhunen, T., Smolander, P., Ilander, T., Rintala, K., Katajainen, T.,
Niemelä, J., Juusela, M., and Palos, T. 2009. "Performance of an Air Sampler and a Gamma-Ray Detector in a Small Unmanned Aerial Vehicle." Journal of Radioanalytical and Nuclear Chemistry 282: 433-7.

[15] Aylor, D. E., Schmale, D. G., Shields, E. J., Newcomb, M., and Nappo, C. J. 2011. "Tracking the Potato Late Blight Pathogen in the Atmosphere Using Unmanned Aerial Vehicles and Lagrangian Modeling." Agricultural and Forest Meteorology 151: 251-60.

[16] Restás, Á., and Dudás, Z. 2013. "Human Aspects and Special Features of UAV Use Supporting Disaster Management." Repüléstudományi Közlemények 25: 23-45. (in Hungarian)

[17] Gademer, A., Petitpas, B., Mobaied, S., Beaudoin, L., Riera, B., Roux, M., and Rudant, J. P. 2010. "Developing a Lowcost Vertical Take Off and Landing Unmanned Aerial System for Centimetric Monitoring of Biodiversity the Fontainebleau Forest Case." In Proceedings of Geoscience and Remote Sensing Symposium (IGARSS), 2010 IEEE International, 600-3.

[18] Svejkovsky, J., Nezlin, N. P., Mustain, N. M., and Kum, J. B. 2010. "Tracking Stormwater Discharge Plumes and Water Quality of the Tijuana River with Multispectral Aerial Imagery." Estuarine, Coastal and Shelf Science 87: 387-98.

[19] Leifer, I., William, J., Lehr, W. J., Simecek-Beatty, D., Bradley, E., Clark, R., Dennison, P., Hu, Y., Matheson, S., Jones, C. E., Holt, B., Reif, M., Roberts, D. A., Svejkovsky, J., Swayze, G., and Wozencraft, J. 2012. "State of the Art Satellite and Airborne Marine Oil Spill Remote Sensing: Application to the BP Deepwater Horizon Oil Spill." Remote Sensing of Environment 124: 185-209. 